\title{
Modeling Chloride Diffusion Coefficient of Steel Fiber Reinforced Concrete under Bending Load
}

\author{
Qiannan Wang $\mathbb{D}^{1},{ }^{1}$ Wei Sun, ${ }^{1,2}$ Liping Guo $\mathbb{D}^{1,2}$ Chunping Gu $\mathbb{D}^{1,}{ }^{3}$ and Jinyu Zong ${ }^{1}$ \\ ${ }^{1}$ School of Materials Science \& Engineering, Southeast University, Nanjing 211189, China \\ ${ }^{2}$ Jiangsu Key Laboratory of Construction Materials, Nanjing 211189, China \\ ${ }^{3}$ College of Civil Engineering and Architecture, Zhejiang University of Technology, Hangzhou 310014, China \\ Correspondence should be addressed to Qiannan Wang; wqnseu@163.com
}

Received 13 August 2017; Accepted 20 December 2017; Published 4 April 2018

Academic Editor: Song Han

Copyright $\odot 2018$ Qiannan Wang et al. This is an open access article distributed under the Creative Commons Attribution License, which permits unrestricted use, distribution, and reproduction in any medium, provided the original work is properly cited.

The chloride diffusion coefficient is the most important parameter when predicting chloride ingress in concrete. This paper proposed a model for calculating the chloride diffusion coefficient of steel fiber reinforced concrete (SFRC). Considering the concrete structures in service are usually subjected to external loads, the effect of bending load was discussed and expressed with a stress factor $k_{\mathrm{s}}$ in the model. The chloride diffusion coefficient of cement paste was calculated with capillary porosity and then used to predict the chloride diffusion coefficient of SFRC. Some factors in the model were determined with experimental results. Chloride bulk diffusion tests were performed on SFRC and plain concrete (without fiber) specimens under bending load. SFRC showed slightly better chloride resistance for unstressed specimens. The compressive stress decreased the chloride diffusion coefficient of SFRC, while it caused no change in plain concrete. For the tensile zone, the chloride resistance of concrete was improved significantly by adding steel fibers. Overall, SFRC performed better chloride resistance, especially under bending load. The proposed model provides a simple approach for calculating the chloride diffusion coefficient of SFRC under bending load.

\section{Introduction}

Chloride-induced rebar corrosion is one of the major forms of environmental attack to reinforced concrete, which may lead to reduction in the strength, serviceability, and esthetics of the concrete structures $[1,2]$. Moreover, cracks caused by mechanical loads reduce the chloride resistance of concrete and speed up the initiation of steel corrosion in concrete, which frequently occurs in field applications [3]. The addition of steel fibers significantly improves the resistance of concrete to crack initiation and propagation [4]. It is also generally accepted that steel fiber reinforced concrete (SFRC) has better durability than plain concrete [5]. However, the effect of steel fibers on chloride transport has not been fully understood yet.

Some work has been carried out over the past few decades to investigate the chloride transport property of SFRC $[6,7]$. Mangat and Gurusamy [3] found that steel fibers had an insignificant effect on chloride transport. Roque et al. [5] observed that SFRC exhibited lower rates of chloride diffusion compared with plain concrete, although the reduction was generally small. On the contrary, El-Dieb [8] observed that an increasing fibers' volume fraction leads to a slightly higher chloride diffusion coefficient. Considering the disagreements in the observed results, the chloride transport property of SFRC needs to be further studied and the effects of steel fibers need to be discussed. Besides, limited work has been performed on chloride transport property of SFRC under bending load. The study on prediction of chloride ingress in SFRC under load is also scarce.

The chloride diffusion coefficient is the most important parameter when predicting the chloride ingress in concrete. The intention of this paper is to present a model for predicting the chloride diffusion coefficient of SFRC under bending load. Besides, the effect of steel fibers on the chloride transport in concrete was investigated with bulk diffusion tests. The chloride diffusion coefficients of SFRC under compression and tension were determined and discussed. 


\section{Chloride Diffusion Theory}

2.1. Fick's Second Law. The mechanism of chloride transport into concrete structures is a rather complicated process [9]. For simplicity's sake, all kinds of chloride transport mechanisms in concrete are generally regarded as "apparent diffusion." By assuming that the chloride diffusion coefficient is constant, the well-known analytical solution of Fick's second law of diffusion is

$$
C(x, t)=C_{s}\left(1-\operatorname{erf} \frac{x}{2 \sqrt{D t}}\right),
$$

where $C(x, t)$ is chloride concentration at depth $x$ and immersion time $t, C_{s}$ is chloride concentration at the surface, $x$ is depth, $t$ is immersion time, and $D$ is chloride diffusion coefficient.

2.2. Time-Dependent Chloride Diffusion Coefficient. The chloride diffusion coefficient of concrete is not constant but decreases over time due to the continuous hydration [10-12]. Tang and Nilsson $[13,14]$ proposed the mathematical expression for a time-dependent chloride diffusion coefficient based on Crank's mathematics of diffusion [14]:

$$
D(t)=a \cdot t^{-n}
$$

where $D(t)$ is the time-dependent diffusion coefficient, $t$ is the concrete age, and $a$ and $n$ are constants, with $n$ normally being referred to as the age factor. With a pair of known diffusion coefficient and age, represented by $D_{0}$ and $t_{0}$, (2) can be rewritten as

$$
D(t)=D_{0} \cdot t_{0}^{n} \cdot t^{-n}=D_{0} \cdot\left(\frac{t}{t_{0}}\right)^{-n} .
$$

The analytical solution of Fick's second law can only be derived under the assumption that the chloride diffusion coefficient is constant. Therefore, mathematical treatment needs to be done to the time-dependent chloride diffusion coefficient to get an average coefficient, which is defined as apparent chloride diffusion coefficient $D_{\mathrm{a}}$ as given in the below equation:

$D_{\mathrm{a}}=\frac{\int D(t) d t}{t}=\frac{D_{0}}{(1-n)} \cdot\left[\left(1+\frac{t_{\mathrm{s}}}{t_{\mathrm{d}}}\right)^{1-n}-\left(\frac{t_{\mathrm{s}}}{t_{\mathrm{d}}}\right)^{1-n}\right] \cdot\left(\frac{t_{0}}{t_{\mathrm{d}}}\right)^{n}$,

where $t_{\mathrm{s}}$ and $t_{\mathrm{d}}$ are the age when concrete starts to be exposed to chlorides and exposure duration, respectively.

Strictly speaking, the apparent diffusion coefficient $D_{\text {a }}$ instead of $D(t)$ can be used in the analytical solution of Fick's second law and (1) can be rewritten as

$$
C(x, t)=C_{\mathrm{s}}\left(1-\operatorname{erf} \frac{x}{2 \sqrt{D_{\mathrm{a}} t}}\right) .
$$

If the age factor $n$ is determined, the apparent chloride diffusion coefficient can be calculated with a pair of $D_{0}$ and $t_{0}$. Consequently, the chloride distribution in concrete after certain immersion time can be predicted with (5).
2.3. Modeling Chloride Diffusion Coefficient D. SFRC consists of cement paste, aggregate, and steel fibers. Compared with cement paste, the aggregate and steel fibers can be considered as impermeable. The chloride diffusion coefficient of SFRC at time $t_{0}$ can be expressed as

$$
D_{0}=D_{0}^{\mathrm{p}} \cdot\left[1-\left(V_{\mathrm{a}}+V_{\mathrm{f}}\right)\right] \cdot k_{\mathrm{m}} \cdot k_{\mathrm{s}}
$$

where $D_{0}^{\mathrm{p}}$ is the chloride diffusion coefficient of cement paste at time $t_{0}, V_{\mathrm{a}}$ and $V_{\mathrm{f}}$ are the volume fractions of aggregate and steel fibers in SFRC, respectively. $V_{\mathrm{a}}$ and $V_{\mathrm{f}}$ can easily be obtained with the mix proportions of SFRC. $k_{\mathrm{m}}$ is a correction factor reflecting the effects of aggregate and steel fibers on chloride transport in SFRC. $k_{\mathrm{s}}$ is the stress factor $\left(k_{\mathrm{s}}\right.$ is 1 for concrete under no stress).

The presence of aggregate and steel fibers leads to formation of interfacial transition zone (ITZ) between the paste and the aggregate/fibers in SFRC. Due to its higher porosity and bigger pore size, ITZ has much higher diffusivity than paste. As a result, the presence of ITZ increases the rate of chloride transport in concrete. On the other hand, the presence of aggregate increases the tortuosity of chloride's transport path in concrete and consequently decreases the chloride diffusivity. Moreover, steel fibers can restrain the crack initiation and propagation, and the high relative surface area of fibers can adsorb some chlorides and retard the chloride ingress. It requires a lot of work to study these effects of aggregate and fibers on chloride transport in SFRC. For simplicity, in this study, the factor $k_{\mathrm{m}}$ was introduced to describe the influences of aggregate and steel fibers on chloride transport in SFRC.

Cracks caused by mechanical loads create easy path for chloride transport and speed up the chloride ingress in concrete, which frequently occurs in field applications $[15,16]$. Therefore, to consider the effects of stress on chloride diffusion coefficient of SFRC, a stress factor $k_{s}$ was introduced in (6). $k_{\mathrm{s}}$ is dependent on the property of concrete and the stress conditions. The values of $k_{\mathrm{m}}$ and $k_{\mathrm{s}}$ were determined with the test results.

There are several models predicting the chloride diffusion coefficient of cement paste [17-20]. The model proposed by Garboczi and Bentz [17] is adopted in this study and shown in the below equation:

$$
\frac{D_{0}^{\mathrm{p}}}{D_{\mathrm{Cl}}}=0.001+0.07 \phi^{2}+H(\phi-0.18) \times 1.8 \times(\phi-0.18)^{2},
$$

where $D_{\mathrm{Cl}}$ is the diffusion coefficient of chloride in bulk water $\left(D_{\mathrm{Cl}}\right.$ is $2.03 \times 10^{-9} \mathrm{~m}^{2} / \mathrm{s}$ at $\left.25^{\circ} \mathrm{C}\right), \phi$ is the capillary porosity of cement paste at time $t_{0} ; H$ is the Heaviside function such that $H(x)=1$ for $x>0$ and $H(x)=0$ for $x \leq 0$. The relationship is suitable for cement paste with a capillary porosity range of $0<\phi<0.6$.

Sun [21] performed mercury intrusion porosimetry (MIP) test on the paste specimen with the same mix proportions and the same materials as the paste of concrete in this study. The MIP test was performed at the age of 60 days. The capillary porosity $\phi$ was $17.45 \%$. Substituting the value of $\phi$ in (7), the chloride diffusion coefficient $D_{0}^{\mathrm{p}}$ of cement 
TABLE 1: Mixture proportions.

\begin{tabular}{|c|c|c|c|c|c|c|c|c|}
\hline & Cement $\left(\mathrm{kg} / \mathrm{m}^{3}\right)$ & FA $\left(\mathrm{kg} / \mathrm{m}^{3}\right)$ & Sand $\left(\mathrm{kg} / \mathrm{m}^{3}\right)$ & Gravel $\left(\mathrm{kg} / \mathrm{m}^{3}\right)$ & Water $\left(\mathrm{kg} / \mathrm{m}^{3}\right)$ & $w / b^{*}$ ratio & $V_{\mathrm{f}}(\%)$ & $V_{\mathrm{a}}+V_{\mathrm{f}}$ \\
\hline C50 & 315 & 135 & 663 & 1179 & 158 & 0.35 & - & 0.687 \\
\hline C50-1 & 370 & 158 & 779 & 917 & 185 & 0.35 & 1 & 0.644 \\
\hline C50-1.5 & 379 & 163 & 799 & 834 & 189 & 0.35 & 1.5 & 0.625 \\
\hline
\end{tabular}

$* w / b$ : water/binder.

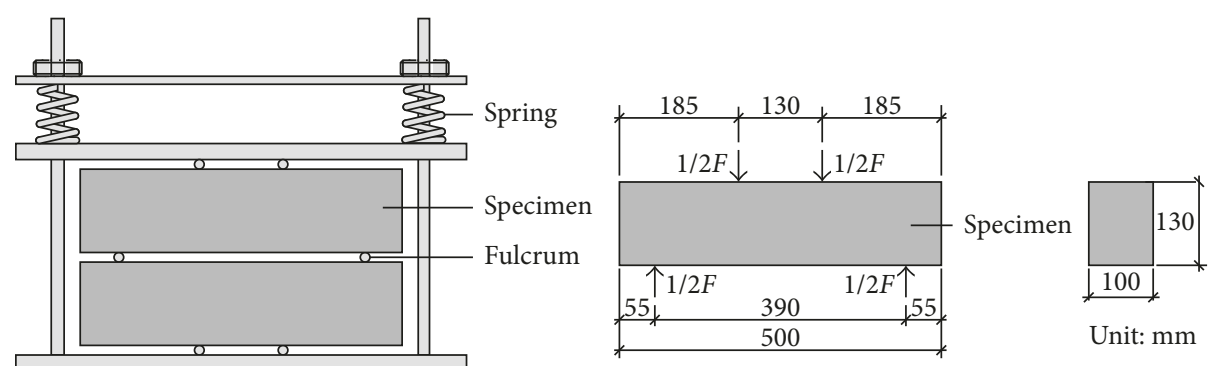

Figure 1: Loading device for the chloride bulk diffusion test.

paste at time $t_{0}\left(t_{0}=60 \mathrm{~d}\right)$ was calculated to be $6.36 \times 10^{-12} \mathrm{~m}^{2} / \mathrm{s}$. If the factors $k_{\mathrm{m}}$ and $k_{\mathrm{s}}$ are determined, the chloride diffusion coefficient $D_{0}$ at time $t_{0}$ can be predicted with (6), and the apparent chloride diffusion coefficient $D_{\mathrm{a}}$ can be calculated with (4), consequently.

\section{Experimental Program}

3.1. Materials and Mixture Proportions. Mixture proportions of the concrete used in this study are given in Table 1. C50 was plain concrete without fiber. C50-1 and C50-1.5 were concrete with steel fibers of $1 \%$ and $1.5 \%$ in volume fraction, respectively. The materials used in this study were P.II52.5R Portland cement; Class I fly ash (FA); natural sand with a maximum grain size of $4.75 \mathrm{~mm}$ and a density of $2650 \mathrm{~kg} / \mathrm{m}^{3}$; gravel with size ranging from 5 to $20 \mathrm{~mm}$ and a density of $2700 \mathrm{~kg} / \mathrm{m}^{3}$; water; and hooked steel fibers with a diameter of $0.65 \mathrm{~mm}$ and a length of $35 \mathrm{~mm}$.

The mixture was cast into $500 \mathrm{~mm} \times 130 \mathrm{~mm} \times 100 \mathrm{~mm}$ molds. After 24 hours curing in molds, the specimens were demolded and cured in standard condition $\left(20^{\circ} \mathrm{C}\right.$, $\mathrm{RH}>95 \%)$ till the age of 90 days.

3.2. Bulk Diffusion Test. Chloride bulk diffusion tests were performed on specimens according to NT Build 443 [22]. For the specimens under load, bending stress was applied through loading device (Figure 1) during the diffusion test. Due to the varying flexural strengths of concretes, it is widely adopted that the stress level (ratio of the applied stress to the ultimate strength), instead of bending load, is set to be identical when studying the effect of stress on chloride resistance of concrete. Stress level is defined as the ratio of applied stress to the ultimate strength. The studied bending load was set at a stress level of 0.5 , and the detailed information about the bending load is given in Table 2. The specimens were submerged in a 3.5\% sodium chloride $(\mathrm{NaCl})$ solution from the age of 90 days.

After 60 days, 90 days, and 150 days immersion, respectively, specimens were taken out to determine the water-soluble
TABLE 2: Flexural strength and bending load (at a stress level of 0.5) at 90 days.

\begin{tabular}{lccc}
\hline & C50 & C50-1 & C50-1.5 \\
\hline Flexural strength (MPa) & 5.87 & 8.69 & 9.16 \\
Bending load in bulk diffusion tests $(\mathrm{kN})$ & 13.7 & 18.9 & 19.8 \\
\hline
\end{tabular}

chloride contents, namely, free chloride in concrete according to JTJ 270-98 [23]. By using the least squares nonlinear regression, the measured chloride profiles were fitted to (5), and the apparent chloride diffusion coefficients were determined.

\section{Results and Discussion}

4.1. Apparent Chloride Diffusion Coefficients $D_{a}$. Based on (5), the apparent chloride diffusion coefficient $D_{\mathrm{a}}$ was found by iteration. Results of $D_{\mathrm{a}}$ for different immersion times are shown in Figure 2. As discussed above, the apparent chloride diffusion coefficients of both plain concrete and SFRC were not constant but decreased over time, no matter what the stress condition was.

For unstressed concrete, there was a slight decreasing tendency in diffusion coefficients with the increase of steel fiber fraction. Roque et al. [5] observed a similar phenomenon in their study as well. This maybe because the steel fiber could restrain the shrinkage of concrete and hence reduced the quantity and width of the microcracks. Moreover, the steel fibers provided more surface area in concrete to absorb chlorides and retarded the transport process of chloride. However, the using of steel fibers induced more interfacial transition zone which could promote the chloride transport to a certain extent. The apparent change in $D_{\mathrm{a}}$ caused by adding steel fibers is dependent on the composition, microstructure, and properties of concrete. Overall, the adding of steel fibers to C50 concrete in this study improved the chloride resistance slightly. It should be pointed out that it is also possible that the using of steel fibers would increase the chloride diffusion coefficient for a different concrete. 


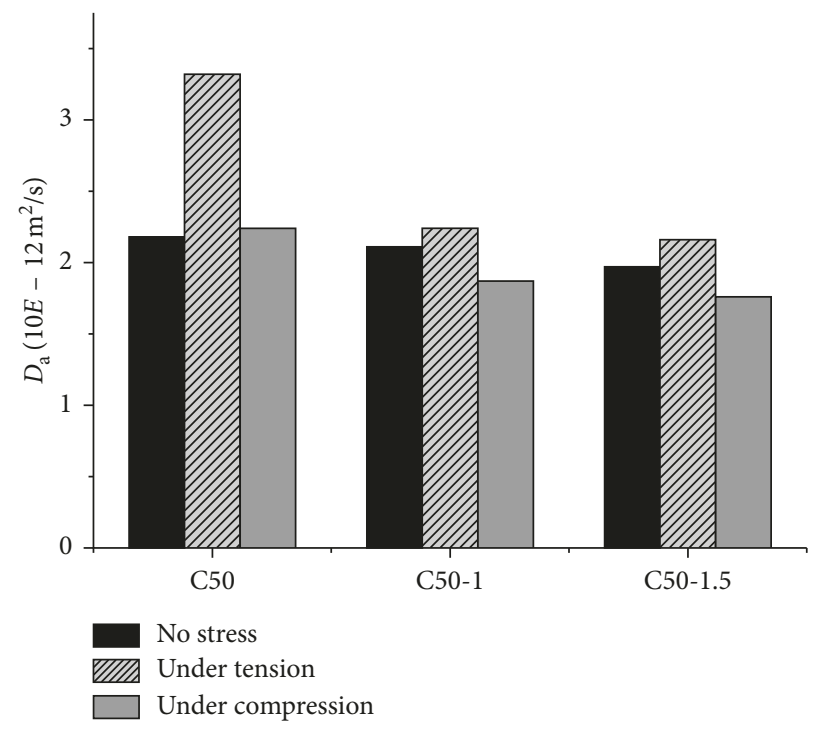

(a)

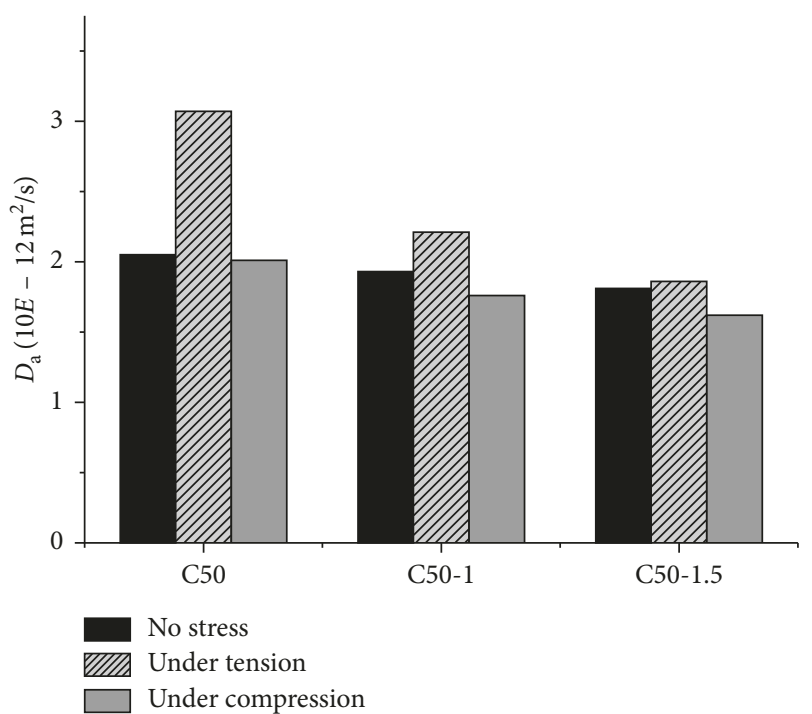

(b)

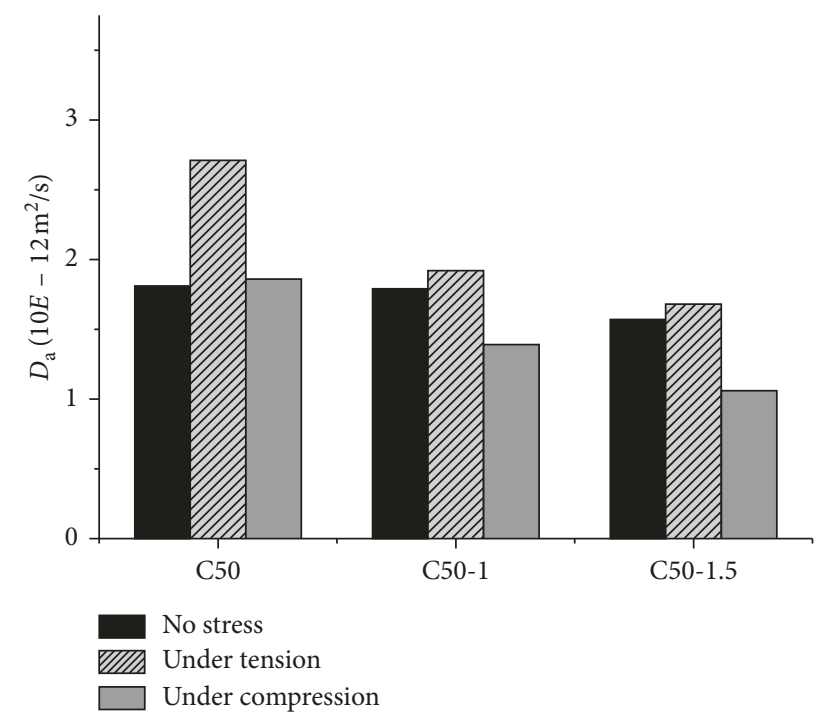

(c)

Figure 2: Results of best-fit apparent chloride diffusion coefficients. Immersion time: (a) $60 \mathrm{~d}$, (b) $90 \mathrm{~d}$, and (c) $150 \mathrm{~d}$.

The effects of stress on $D_{\mathrm{a}}$ varied with different concretes. For plain concrete $\mathrm{C} 50$, the tensile stress had a remarkable influence on chloride transport as expected. The apparent chloride diffusion coefficient of C50 under tension was about $50 \%$ higher than that under no stress. Interestingly, the compressive stress seemed to almost have no effect on chloride transport in C50.

On the other hand, due to the superior resistance of steel fibers to crack initiation and propagation, the apparent chloride diffusion coefficient $D_{\mathrm{a}}$ of C50-1 and C50-1.5 under tension was only a little higher compared with the unstressed ones. And C50-1.5 presented better chloride resistance than C50-1. $D_{\mathrm{a}}$ of C50-1.5 under tension after 150-day immersion was $62 \%$ of that for C50 concrete under the same condition. This means the use of steel fibers can enhance the durability of concrete structures exposed to chloride environments and prolong the service life of structures greatly.
When the SFRC specimens were under compression, $D_{\mathrm{a}}$ was a little lower than the unstressed ones, which was different from the plain concrete C50. At low levels of compressive stress (up to $30 \%$ of ultimate strength), cracks are restricted to the aggregate-paste interface [24], and this results in very little increase in permeability, if any. There is another opposite effect caused by compressive stress, which is consolidation or closing of pore and microcracks, resulting in a decrease in chloride diffusion coefficient. Normally, the pore compaction effect plays a dominant role at low stress levels and leads to a reduction in chloride diffusion coefficient. When the compressive stress increases, the cracks start to propagate and getting wider. The reduction in $D_{\mathrm{a}}$ due to pore compaction can be counteracted by the growing cracks. When the stress is beyond some critical level, $D_{\mathrm{a}}$ would increase rapidly with the rising of stress level. The sensitivities of concretes to compressive stress level vary with different concretes. This may 
TABLE 3: Results of chloride diffusion coefficient $D_{0}\left(\times 10^{-12} \mathrm{~m}^{2} / \mathrm{s}\right)\left(t_{0}=60 \mathrm{~d}\right)$.

\begin{tabular}{|c|c|c|c|c|c|c|c|c|c|}
\hline \multirow{2}{*}{$\begin{array}{l}\text { Immersion time } \\
\text { (days) }\end{array}$} & \multicolumn{3}{|c|}{$\mathrm{C} 50$} & \multicolumn{3}{|c|}{ C50-1 } & \multicolumn{3}{|c|}{ C50-1.5 } \\
\hline & $\begin{array}{c}\text { No } \\
\text { stress }\end{array}$ & $\begin{array}{l}\text { Under } \\
\text { tension }\end{array}$ & $\begin{array}{c}\text { Under } \\
\text { compression }\end{array}$ & $\begin{array}{c}\text { No } \\
\text { stress }\end{array}$ & $\begin{array}{l}\text { Under } \\
\text { tension }\end{array}$ & $\begin{array}{c}\text { Under } \\
\text { compression }\end{array}$ & $\begin{array}{c}\text { No } \\
\text { stress }\end{array}$ & $\begin{array}{l}\text { Under } \\
\text { tension }\end{array}$ & $\begin{array}{c}\text { Under } \\
\text { compression }\end{array}$ \\
\hline 60 & 3.47 & 5.29 & 3.57 & 3.36 & 3.57 & 2.98 & 3.14 & 3.44 & 2.80 \\
\hline 90 & 3.51 & 5.25 & 3.44 & 3.30 & 3.78 & 3.01 & 3.10 & 3.18 & 2.77 \\
\hline 150 & 3.48 & 5.21 & 3.58 & 3.44 & 3.69 & 2.67 & 3.02 & 3.23 & 2.04 \\
\hline Average of $D_{0}$ & 3.49 & 5.25 & 3.53 & 3.37 & 3.68 & 2.89 & 3.08 & 3.28 & 2.54 \\
\hline
\end{tabular}

explain why the plain concrete and SFRC responded differently to the same compressive stress level.

4.2. Chloride Diffusion Coefficient $D_{0}$ at Age of $t_{0}$. The age factor $n$ is an important parameter for determining the time dependent chloride diffusion coefficient. Both water/cement ratio and admixtures have important impacts on $n$ [25]. Markeset and Skjølsvold [26] recommended that the age factor of concrete with more than 20\% FA was 0.60 in fib Model Code for Service Life Design. DuraCrete [27] suggested an age factor of 0.69 for concrete containing FA in a submerged environment. Considering the concrete in this study which contained $30 \%$ FA, a value of 0.69 recommended by DuraCrete was adopted. Further research is still needed for the determination of $n$ in the future.

Given $t_{0}=60 \mathrm{~d}$, the chloride diffusion coefficient $D_{0}$ is defined as the chloride diffusion coefficient of concrete at the age of 60 days. With three pairs of $D_{\mathrm{a}}$ and $t_{\mathrm{d}}$ (immersion time), three values of $D_{0}$ could be obtained with (4) and an averaged value was determined as $D_{0}$ (Table 3 ). The tendency of $D_{0}$ was consistent with $D_{\mathrm{a}}$. In other words, $D_{0}$ of SFRC under no stress was slightly lower than plain concrete. For stressed specimens, $D_{0}$ of SFRC was much lower compared with plain concrete, especially under tensile stress.

4.3. Factors $k_{m}$ and $k_{s}$. The stress factor $k_{\mathrm{s}}$ was determined as the ratio of $D_{0}$ under stress to $D_{0}$ without stress. For concrete under no stress, $k_{\mathrm{s}}=1$ and (6) becomes

$$
D_{0}=D_{0}^{\mathrm{p}} \cdot\left[1-\left(V_{\mathrm{a}}+V_{\mathrm{f}}\right)\right] \cdot k_{\mathrm{m}} .
$$

The total volume fraction of aggregate and steel fibers was calculated with the mix proportions and is given in Table 1 . With known $D_{0}$ and $D_{0}^{\mathrm{p}}$ for concrete under no stress, the values of $k_{\mathrm{m}}$ were calculated with (8). The results of $k_{\mathrm{m}}$ and $k_{\mathrm{s}}$ are shown in Table 4

As seen in Table $4, k_{\mathrm{m}}$ decreased as the volume fraction of steel fibers increased. This indicated that the addition of steel fibers had positive effect on retarding the chloride ingress in concrete. $k_{\mathrm{s}}$ varies with the stress type and stress level. Actually, both $k_{\mathrm{m}}$ and $k_{\mathrm{s}}$ depend on the composition and properties of concrete. It requires more data to establish a relationship between $k_{\mathrm{m}}$ (or $k_{\mathrm{s}}$ ) and some information/properties (e.g., fiber dosage and porosity .) of concrete. Therefore, the next step is to obtain more data about the chloride transport property of SFRC and build equations for determining $k_{\mathrm{m}}$ and $k_{\mathrm{s}}$. After that, the chloride diffusion coefficient $D_{0}$ at time $t_{0}$ can be calculated with (6), and the
TABLE 4: Results of $k_{\mathrm{m}}$ and $k_{\mathrm{s}}$.

\begin{tabular}{lcccc}
\hline & \multirow{2}{*}{$k_{\mathrm{m}}$} & \multicolumn{3}{c}{$k_{\mathrm{s}}$ (bending load, stress level: 0.5) } \\
& & No stress & Under tension & Under compression \\
\hline C50 & 1.75 & 1 & 1.50 & 1.01 \\
C50-1 & 1.49 & 1 & 1.09 & 0.86 \\
C50-1.5 & 1.29 & 1 & 1.06 & 0.82 \\
\hline
\end{tabular}

apparent chloride diffusion coefficient $D_{\text {a }}$ can be obtained with (4), consequently. Finally, the chloride ingress in SFRC can be evaluated with Fick's second law and its solution (5).

\section{Conclusions}

This paper proposed a model for calculating the chloride diffusion coefficient of SFRC under bending load. The chloride bulk diffusion tests were performed on SFRC and plain concrete specimens to investigate the chloride resistance of SFRC under load and determine some factors in the model. The results obtained are summarized below.

(1) The chloride resistance of unstressed SFRC was slightly better compared with unstressed plain concrete. For concrete under bending load at a stress level of 0.5 , the apparent chloride diffusion coefficient of SFRC in the tensile zone was about $40 \%$ lower than that of plain concrete. The compressive stress seemed to have no apparent effect on the chloride transport in plain concrete. On the other hand, the chloride transport in SFRC was a little retarded by compressive stress. Overall, the addition of steel fibers could improve the chloride resistance of concrete and consequently prolong the service life of reinforced concrete in chloride environment.

(2) The chloride diffusion coefficient $D_{0}^{\mathrm{p}}$ of cement paste was calculated with capillary porosity. It was then used to predict the chloride diffusion coefficient $D_{0}$ of SFRC at time $t_{0}$. The effect of bending load was investigated by introducing a stress factor $k_{s}$.

(3) Considering the time dependence of chloride diffusion coefficient, it is apparent that chloride diffusion coefficient $D_{\mathrm{a}}$ was used when predicting the chloride ingress in concrete. $D_{\mathrm{a}}$ can be calculated with a pair of chloride diffusion coefficient $D_{0}$ and time $t_{0}$. Consequently, the chloride distribution in concrete at any time can be predicted with $D_{\mathrm{a}}$.

\section{Conflicts of Interest}

The authors declare that they have no conflicts of interest. 


\section{Acknowledgments}

This work was supported by a technical research program from NV Bekaert SA of Belgium, the National Natural Science Foundation of China (Grant nos. 1378113, 51438003, and 51278098), and a Plan of Six Peak Talents in Jiangsu Province (Grant no. JZ-004) and was partly supported by a National Basic Research Program of China (973 Program with Grant no. 2015CB655102).

\section{References}

[1] B. Gérard and J. Marchand, "Influence of cracking on the diffusion properties of cement-based materials: part I: influence of continuous cracks on the steady-state regime," Cement and Concrete Research, vol. 30, no. 1, pp. 37-43, 2000.

[2] P. K. Mehta, "Concrete durability-fifty years progress," in Proceedings of 2nd International Conference on Concrete Durability, pp. 1-31, Montreal, QC, Canada, August 1991.

[3] P. S. Mangat and K. Gurusamy, "Chloride diffusion in steel fiber reinforced marine concrete," Cement and Concrete Research, vol. 17, no. 3, pp. 385-396, 1987.

[4] C. Miao, R. Mu, Q. Tia, and W. Sun, "Effect of sulfate solution on the frost resistance of concrete with and without steel fiber reinforcement," Cement and Concrete Research, vol. 32, no. 1, pp. 31-34, 2002.

[5] R. Roque, N. Kim, B. Kim, and G. Lopp, Durability of FiberReinforced Concrete in Florida Environments, Florida Department of Transportation, Tallahassee, FL, USA, 2009.

[6] C. G. Berrocal, K. Lundgren, and I. Löfgren, "Corrosion of steel bars embedded in fibre reinforced concrete under chloride attack: state of the art," Cement and Concrete Research, vol. 80, pp. 69-85, 2015.

[7] C. P. Gu, G. Ye, and W. Sun, "A review of the chloride transport properties of cracked concrete: experiments and simulations," Journal of Zhejiang University-SCIENCE A, vol. 16, no. 2, pp. 81-92, 2015.

[8] A. S. El-Dieb, "Mechanical, durability and microstructural characteristics of ultra-high-strength self-compacting concrete incorporating steel fibers," Materials and Design, vol. 30, no. 10, pp. 4286-4292, 2009.

[9] R. D. Hooton and P. F. McGrath, "Issues related to recent developments in service life specifications for concrete structures," in Proceedings of the 1st RILEM Workshop on Chloride Penetration into Concrete, pp. 388-397, Saint Rémy-les Chevreuse, France, 1997.

[10] K. Audenaert, Q. Yuan, and G. De Schutter, "On the time dependency of the chloride migration coefficient in concrete," Construction and Building Materials, vol. 24, no. 3, pp. 396-402, 2010.

[11] M. Nokken, A. Boddy, R. D. Hooton, and M. D. A. Thomas, "Time dependent diffusion in concrete-three laboratory studies," Cement and Concrete Research, vol. 36, no. 1, pp. 200-207, 2006.

[12] S. W. Pack, M. S. Jung, H. W. Song, S. H. Kim, and K.Y. Ann, "Prediction of time dependent chloride transport in concrete structures exposed to a marine environment," Cement and Concrete Research, vol. 40, no. 2, pp. 302-312, 2010.

[13] L. Tang and L. O. Nilsson, "Chloride diffusivity in high strength concrete at different ages," Nordic Concrete Research, vol. 11, no. 1, pp. 162-171, 1992.

[14] J. Crank, The Mathematics of Diffusion, Oxford University Press, Oxford, UK, 1979.
[15] G. Lin, Y. Liu, and Z. Xiang, "Numerical modeling for predicting service life of reinforced concrete structures exposed to chloride environments," Cement and Concrete Composites, vol. 32, no. 8, pp. 571-579, 2010.

[16] P. N. Faye, Y. H. Ye, and B. Diao, "Bond effects between concrete and steel bar using different diameter bars and different initial crack width," Advances in Civil Engineering, vol. 2017, Article ID 8205081, 11 pages, 2017.

[17] E. J. Garboczi and D. P. Bentz, "Computer simulation of the diffusivity of cement-based materials," Journal of Materials Science, vol. 27, no. 8, pp. 2083-2092, 1992.

[18] G. W. Sun, W. Sun, Y. S. Zhang, and Z. Y. Liu, "Relationship between chloride diffusivity and pore structure of hardened cement paste," Journal of Zhejiang University-SCIENCE A, vol. 12, no. 5, pp. 360-367, 2011.

[19] J. J. Zheng, X. Z. Zhou, and Z. M. Wu, "A simple method for predicting the chloride diffusivity of cement paste," Materials and Structures, vol. 43, no. 1-2, pp. 99-106, 2010.

[20] K. Maekawa, T. Ishida, and T. Kishi, Multi-Scale Modeling of Structural Concrete, Taylor \& Francis, Hoboken, NJ, USA, 2009.

[21] G. W. Sun, Transport Behaviors and Multi-Scale Modeling of Chloride Ions in Cement-Based Composite Materials, Southeast University, Nanjing, China, 2012.

[22] Nordtest, NT BUILD 443, Concrete, Hardened: Accelerated Chloride Penetration, Nordtest, Espoo, Finland, 1995.

[23] JTJ 270-98, "Testing method for water-soluble chloride ions in mortar of concrete," in Testing Code of Concrete for Port and Waterway Engineering, pp. 202-205, Ministry of Communications of PRC, Beijing, China, 1998.

[24] P. K. Mehta and P. J. Monteiro, Concrete: Microstructure, Properties, and Materials, McGraw-Hill, New York, NY, USA, 3rd edition, 2006.

[25] W. Chalee, C. Jaturapitakkul, and P. Chindaprasirt, "Predicting the chloride penetration of fly ash concrete in seawater," Marine Structures, vol. 22, no. 3, pp. 341-353, 2009.

[26] G. Markeset and O. Skjølsvold, "Time dependent chloride diffusion coefficient: field studies of concrete exposed to marine environment in Norway," in Proceedings of the 2nd International Symposium on Service Life Design for Infrastructures, pp. 83-90, Delft, Netherlands, October 2010.

[27] DuraCrete, Probabilistic Performance based Durability Design of Concrete Structures, General Guidelines for Durability Design and Redesign, Document BE95-1347/R15, DuraCrete, Inc., West Valley City, UT, USA, 2000. 


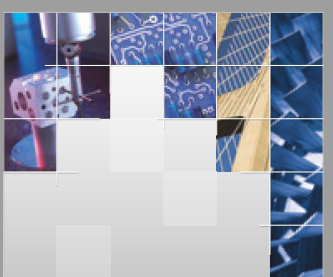

\section{Enfincering}
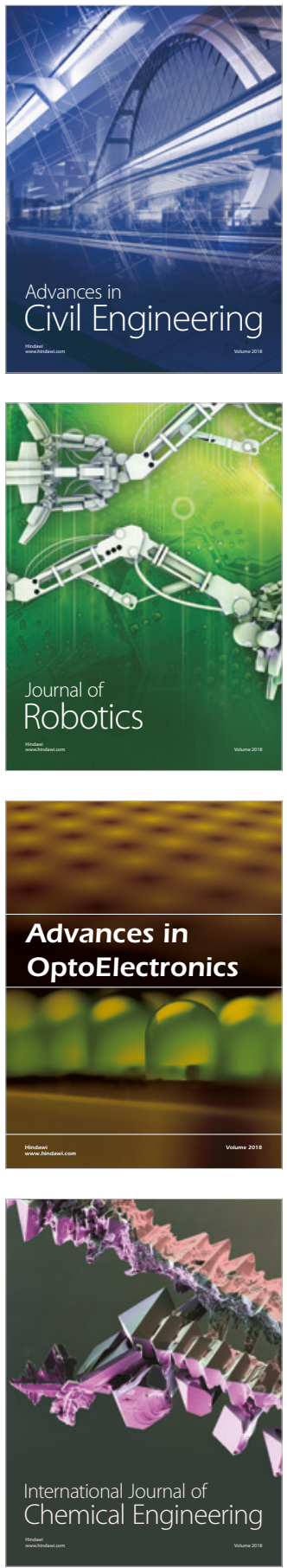

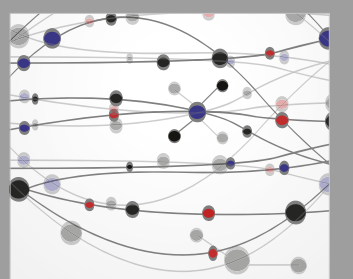

\section{Rotating \\ Machinery}

The Scientific World Journal

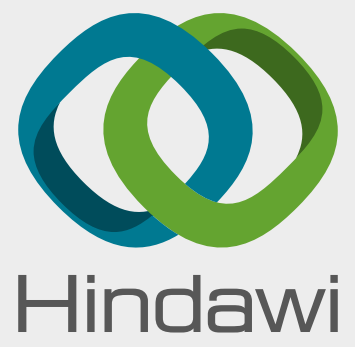

Submit your manuscripts at

www.hindawi.com
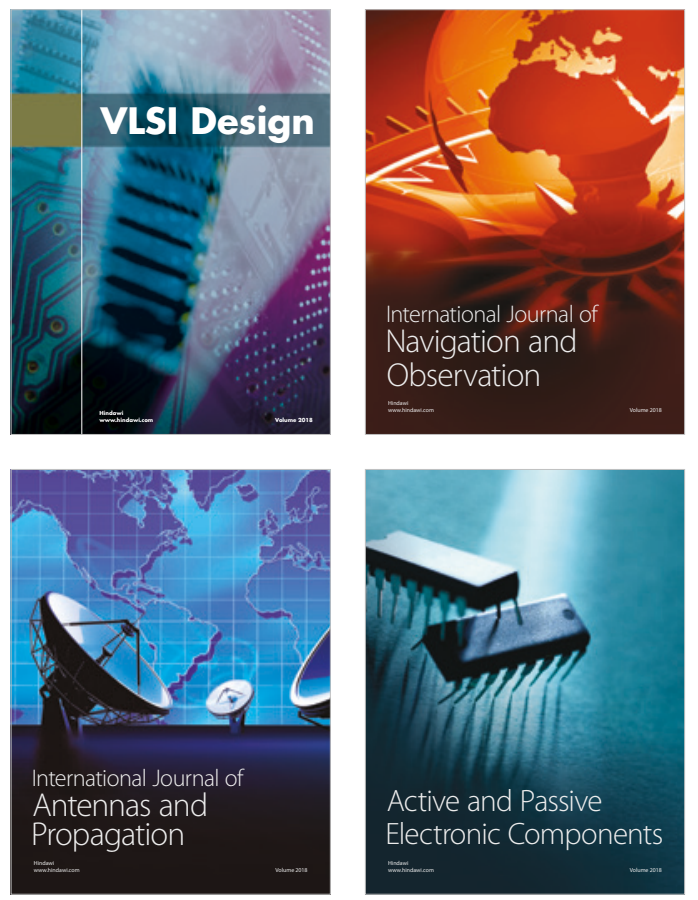
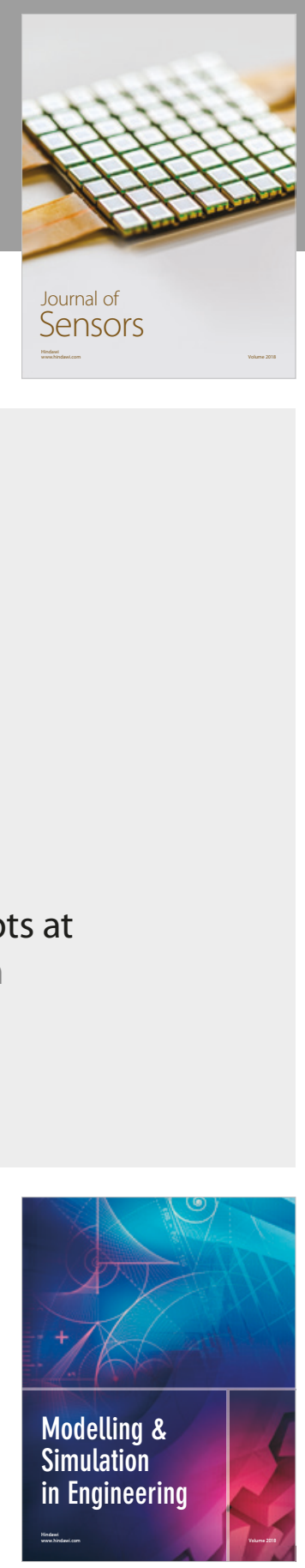

\section{Advances \\ Multimedia}
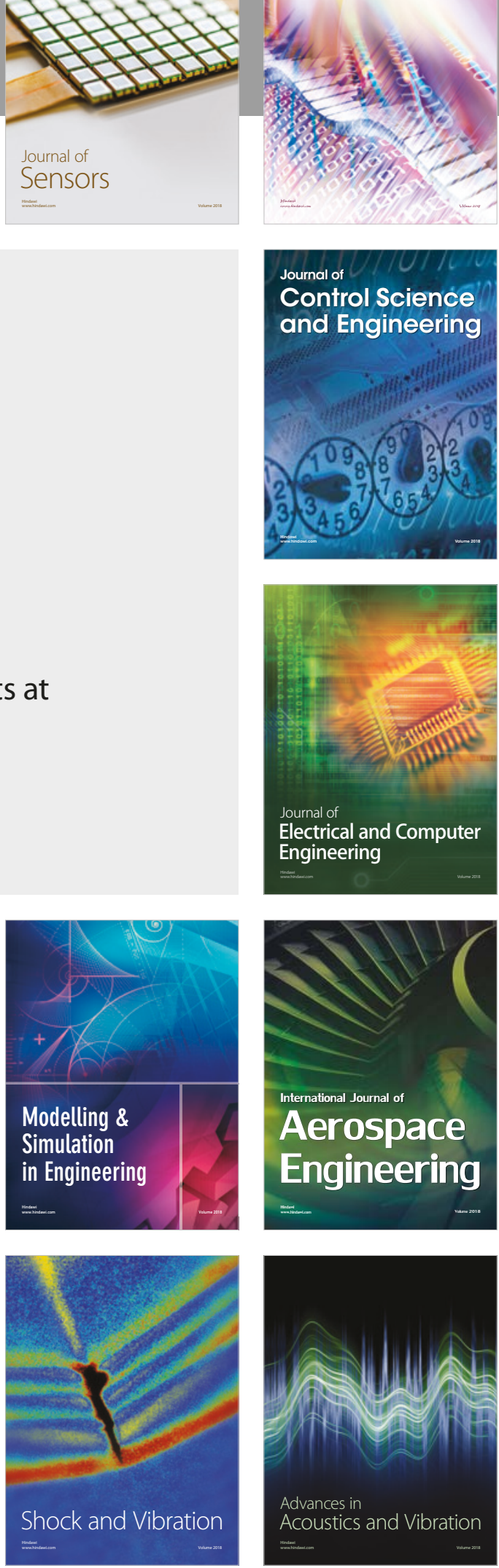